\title{
Assessment of drug therapy problems among patients with cervical cancer at Kenyatta National Hospital, Kenya
}

\author{
Amsalu Degu ${ }^{1 *}$, Peter Njogu ${ }^{2}$, Irene Weru ${ }^{3}$ and Peter Karimi ${ }^{1}$
}

\begin{abstract}
Background: Although cervical cancer is preventable, it is still the second leading cause of cancer deaths among women in the world. Further, it is estimated that around 5-10\% of hospital admissions are due to drug related problems (DRPs), of which 50\% are avoidable. In cancer therapy, there is an immense potential for DRPs due to the high toxicity of most chemotherapeutic regimens. Hence, this study sought to assess DRPs among patients with cervical cancer at Kenyatta National Hospital (KNH).

Methods: A cross-sectional study was conducted at the oncology units of KNH. A total of 81 study participants were recruited through simple random sampling. Data were collected from medical records and interviewing patients. The appropriateness of medical therapy was evaluated by comparing with National Compressive Cancer Network and European Society for Medical Oncology practice guideline of cervical cancer treatment protocol. The degree of adherence was determined using eight-item Morisky medication adherence scale. The likelihood of drug interaction was assessed using Medscape, Micromedex and Epocrates drug interaction checkers. The data were entered in Microsoft Excel and analysed using statistical software STATA version 13.0. Descriptive statistics such as mean, percent and frequency were used to summarise patients' characteristics. Univariable and multivariable binary logistic regression were used to investigate the potential predictors of DRPs.
\end{abstract}

Result: A total of 215 DRPs were identified from 76 patients, translating to a prevalence of $93.8 \%$ and a mean of 2 . $65 \pm 1.22$ DRPs. The predominant proportion of DRPs (48.2\%) was identified in patients who had been treated with chemoradiation regimens. Adverse drug reactions 56(69.1\%) and drug interactions 38(46.9\%) were the most prevalent DRPs. Majority (67.9\%) of the study population were adherent to their treatment regimens. Forgetfulness 18(69.2\%), expensive medications $4(15.4 \%)$ and side effects of medications $4(15.4 \%)$ were the main reasons for medication non-adherence. Patients with advanced stage cervical cancer were 15.4 times $(A O R=15.4,95 \% \mathrm{Cl}=1$. 3-185.87, $p=0.031$ ) more likely to have DRPs as compared to patients with early stage disease.

Conclusion: Adverse drug reactions, drug interactions, and need of additional drug therapy were the most common DRPs identified among cervical cancer patients. Advanced stage cervical cancer was the only predictor of DRPs.

Keywords: Drug related problems, Cervical cancer, Kenyatta national hospital

\footnotetext{
* Correspondence: amsaludegu@yahoo.com

${ }^{1}$ Department of Pharmaceutics and Pharmacy Practice, University of Nairobi,

College of Health Sciences, School of Pharmacy, P.O. Box 19676-00202,

Nairobi, Kenya

Full list of author information is available at the end of the article
} 


\section{Background}

In the past few decades, medicines have had a substantial positive effect on health by reducing mortality and disease burden. Interestingly, there is ample evidence that potential problems exists since the right medicine does not always reach the right patient and around 50\% of all patients fail to take their medication correctly [1]. Moreover, irrational use of drugs is a major global problem, and World Health Organization (WHO) estimates that above $50 \%$ of all drugs are prescribed and dispensed inappropriately with consequent wastage of scarce resources and widespread health hazards [2].

A drug-related problem (DRP) is defined as an event involving drug therapy that has a potential to interfere with the desired health outcomes [3]. Alternatively, a drug therapy problem is any detrimental event experienced by a patient which impedes attainment of the desired goals of treatment. In the absence of appropriate intervention, medication problems have considerable negative impact on the health of the patients [4].

Drug-related problems are categorised into different classes, namely need for additional drug therapy, medication use without indication, improper drug selection, overdosage, sub-therapeutic dosage, adverse drug reactions (ADRs), drug interactions, inappropriate laboratory monitoring and non-adherence [4].

In cancer therapy, there is a tremendous potential for DRPs due to the high toxicity and the complexity of most chemotherapeutic regimens [5]. Cancer patients have a high incidence of coexisting chronic diseases and the treatment of cancer carry an inherent risk of DRPs [6]. Moreover, problems arising due to drugs are more common in cancer patients, and commonly present a major hurdle to health care providers [7].

Drug-related problems due to cancer chemotherapy can have severe consequences arising from the high toxicity and narrow therapeutic range of anticancer drugs [5]. Anticancer agents are differentiated from other class of drugs due to the frequency and severity of side effects at therapeutic doses [8]. Chemoradiation with cisplatin is associated with increased acute haematological and gastrointestinal toxicity in cervical cancer patients [9]. Since cancer patients receive multiple drug therapy, they are at a higher risk to develop DRPs. Accordingly, a substantial clinical need is required to address this problem by identifying cancer therapy-induced problems. Moreover, the prevalence of DRPs in patients with cervical cancer is not known in Kenya though the chemotherapeutic agents are expected to produce serious adverse outcomes to the patients. Thus, it was imperative that assessment was carried out to identify DRPs in cervical cancer patients to overcome these hurdles.

An extensive study of DRPs would render valuable perspicacity for the healthcare providers to lessen the incidence of DRPs [10]. However, there is a paucity of data on comprehensive DRPs among cervical cancer patients. Therefore, this study investigated the prevalence, types and predictors of DRPs in cervical cancer patients admitted at the oncology units of Kenyatta National Hospital.

\section{Methods}

\section{Study design and setting}

A cross-sectional study design was conducted from April to June 2017 at the oncology units of Kenyatta National Hospital (KNH), the biggest tertiary hospital in Kenya. Single population proportion formula was used to calculate the sample size [11].

$$
\mathbf{n}=\frac{\mathbf{Z}_{\frac{\mathbf{\alpha}}{2}}^{2} \times \mathbf{P}(1-\mathbf{P})}{\mathbf{d}^{2}}
$$

where: $\mathrm{n}$ is the minimum sample size required for large population $(\geq 10,000)$.

$Z_{\alpha / 2}$ is the critical value for a $95 \%$ confidence interval (= 1.96 from Z-table).

$\mathrm{P}$ is the proportion of drug-related problems in cervical cancer patients. Since there were no previous studies in Kenya, P was assumed to be $50 \%(0.5)$.

$\mathrm{d}$ is the margin of error $(5 \%)$

Hence, estimated minimum sample size

$$
(\mathrm{n})=\frac{(1.96)^{2} \times 0.5(1-0.5)}{(0.05)^{2}}=384
$$

However, since study population was less than 10,000 , we estimated the sample size using the following reduction formula.

Corrected sample size $=\frac{\mathbf{n} \times \mathbf{N}}{\mathbf{n}+\mathbf{N}}$ Where $\mathrm{N}=$ source population and $\mathrm{n}=$ estimated sample size for $N \geq 10,000$ population. According to $\mathrm{KNH}$ Health Information Department report, an average of 90 cervical cancer patients was on treatment in both inpatient and outpatient oncology units of $\mathrm{KNH}$ in the preceding three months period (September-November, 2016). The study was carried out for three months period, and hence the approximate size of the source population was 90 cervical cancer patients. Then, corrected sample size $=\frac{384 \times 90}{384+90}=73$. Therefore, the corrected sample size with a $10 \%$ contingency for incomplete medical records of the patient and non-response provided a final sample size of 81 cervical cancer patients.

\section{Eligibility criteria}

Patients aged 18 years and above with documented diagnosis of cancer and, treatment regimens were targeted. However, only those who signed the informed consent were included in the study. 


\section{Data collection techniques}

Two qualified nurses from the oncology units of $\mathrm{KNH}$ were trained to assist in data collection. Relevant information about each patient such as socio-demographic characteristics, histological types of cervical cancer, stage of cancer, types of co-morbidity, treatment regimen, ADR, the rate of adherence and reasons for nonadherence, were recorded by reviewing medical records and interviewing the patients. A pilot study was done in $10 \%$ of the sample size to ensure the validity of the data collection instruments. After pre-testing, all necessary adjustments were executed on the data collection instruments before implementing in the main study. The adequacy of medical therapy was evaluated using National Guidelines for Cancer Management in Kenya [12], National Compressive Cancer Network (NCCN) practice guideline of cervical cancer treatment [13], European Society for Medical Oncology (ESMO) practice guideline of cervical cancer [14] and WHO cancer pain management protocols [15]. The probability of drug interaction was assessed using Medscape, Micromedex, Web MD and Epocrates drug interaction checkers. The degree of adherence was determined using Eight-Item Morisky Medication Adherence Scale [16]. The Modification of Diet in Renal Disease (MDRD) Study eq. [17], Du Bois method [18] and Calvert formula [19] were used to determine estimated Glomerular filtration rate (eGFR), body surface area and carboplatin dosing, respectively. DRPs were categorised as the need of additional drug therapy, medication use without indication, improper drug selection, overdosage, sub-therapeutic dosage, adverse drug reactions, drug interactions, inappropriate laboratory monitoring and patient's non-adherence by the Cipolle et al. classification system [4].

\section{Analysis}

The data were entered into the Microsoft Excel worksheet and analysed using statistical software STATA version 13.0. Descriptive statistics such as percent and frequency were used to summarise categorical variables of patients' characteristics. Mean and standard deviation were used to compile continuous variables. The univariable and multivariable binary logistic regression analyses were employed to investigate the potential predictors of DRPs. A $p$-value of $\leq 0.05$ was considered statistically significant.

\section{Results}

\section{Sociodemographic characteristics of study participants}

The study was conducted among 81 cervical cancer patients. The mean age of the study population was $53.3 \pm 11.6$ years, and the predominant portion of the study subjects $47(58.0 \%)$ were aged 50 years and above. Among the 81 study participants, 61(75.3\%) were married, $44(54.3 \%)$ had a primary level of education, while only
$2(2.5 \%)$ had attained tertiary level of education. Twenty four participants $(29.6 \%)$ were housewives. The monthly income level of majority of the population $59(72.8 \%)$ was less than USD 100, and most of the patients 40(49.4\%) were on treatment with 5-9 drugs (Table 1).

\section{Clinical characteristics of the study participants}

As illustrated in Fig. 1, three histological types of cervical cancer were identified among the study subjects. Squamous cell carcinoma (91.4\%) was the most common type, followed by adenocarcinoma (7.4\%) while invasive anaplastic carcinoma (1.2\%) was the least common histological type.

The study showed that $44.4 \%$ and $35.8 \%$ of study population had stage II and III cervical cancer, respectively, with stages IIB (33.3\%) and IIIB (28.4\%) being the most prevalent. However, stages I and IV had low prevalence rates (Fig. 2).

Table 1 Sociodemographic characteristics of the study participants

\begin{tabular}{|c|c|c|}
\hline Variables & Frequency & Percent \\
\hline \multicolumn{3}{|l|}{ Age (years) } \\
\hline 29-39 & 10 & 12.3 \\
\hline $40-50$ & 24 & 29.6 \\
\hline$\geq 51$ & 47 & 58.0 \\
\hline \multicolumn{3}{|l|}{ Marital status } \\
\hline Single & 20 & 24.7 \\
\hline Married & 61 & 75.3 \\
\hline \multicolumn{3}{|l|}{ Level of education } \\
\hline Illiterate & 10 & 12.3 \\
\hline Primary & 44 & 54.3 \\
\hline Secondary & 25 & 30.9 \\
\hline Tertiary & 2 & 2.5 \\
\hline \multicolumn{3}{|l|}{ Occupation } \\
\hline Housewife & 24 & 29.6 \\
\hline Retired & 9 & 11.1 \\
\hline Merchant & 5 & 6.2 \\
\hline Unemployed & 19 & 23.5 \\
\hline Farmer & 16 & 19.8 \\
\hline Daily labourer & 4 & 4.9 \\
\hline Private employee & 3 & 3.7 \\
\hline Other & 1 & 1.2 \\
\hline \multicolumn{3}{|c|}{ Monthly family income (USD) } \\
\hline Very low $(<100)$ & 59 & 72.8 \\
\hline Low (100-200) & 18 & 22.2 \\
\hline Average (200-500) & 4 & 4.9 \\
\hline \multicolumn{3}{|c|}{ Number of drugs per patient } \\
\hline$<5$ & 31 & 38.3 \\
\hline $5-9$ & 40 & 49.4 \\
\hline$>=10$ & 10 & 12.3 \\
\hline
\end{tabular}




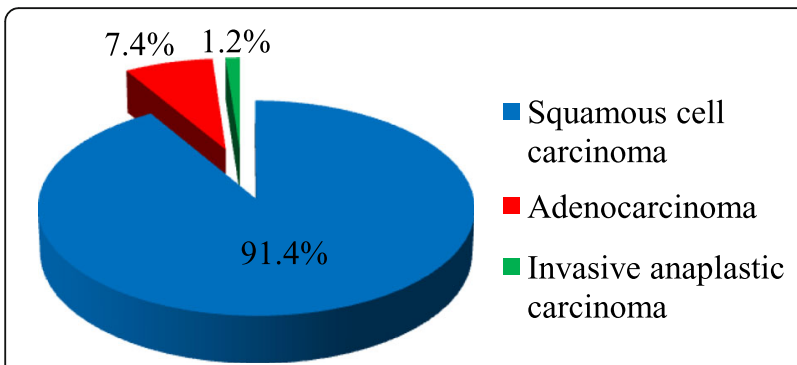

Fig. 1 Histological types of cervical cancer among the study participants

Among the study population, $39.5 \%$ patients did not have co-existing co-morbidities. Nonetheless, 35.8\%, $17.3 \%$, and $3.7 \%$ patients had been diagnosed with one, two, three, and four and above co-morbidities, respectively (Fig. 3). Anaemia 21(25.9\%), retroviral disease 15(18.3\%) and hypertension $13(16.1 \%)$ were the most common types of co-morbidities. Conversely, pulmonary embolism, sepsis, acute kidney injury, goitre and gastric ulcer were the least frequent co-morbidities among the study participants (Table 2). When age was taken into consideration, most of the study participants (29.6\%) who had co-existing comorbidities were aged 51 years and above (Fig. 4).

\section{Types of regimen used in the management of cervical cancer} Chemoradiation $41(50.6 \%)$ comprising of weekly cisplatin and daily radiotherapy was the most widely used treatment regimen in the management of cervical cancer in our setting. Further, hysterectomy and brachytherapy had been used in the management of $15(18.5 \%)$ and $11(13.6 \%)$ of the patients, respectively. Cisplatin and paclitaxel 9(11.1\%) were the most commonly used combination anticancer agents in the treatment of cervical cancer (Table 3).

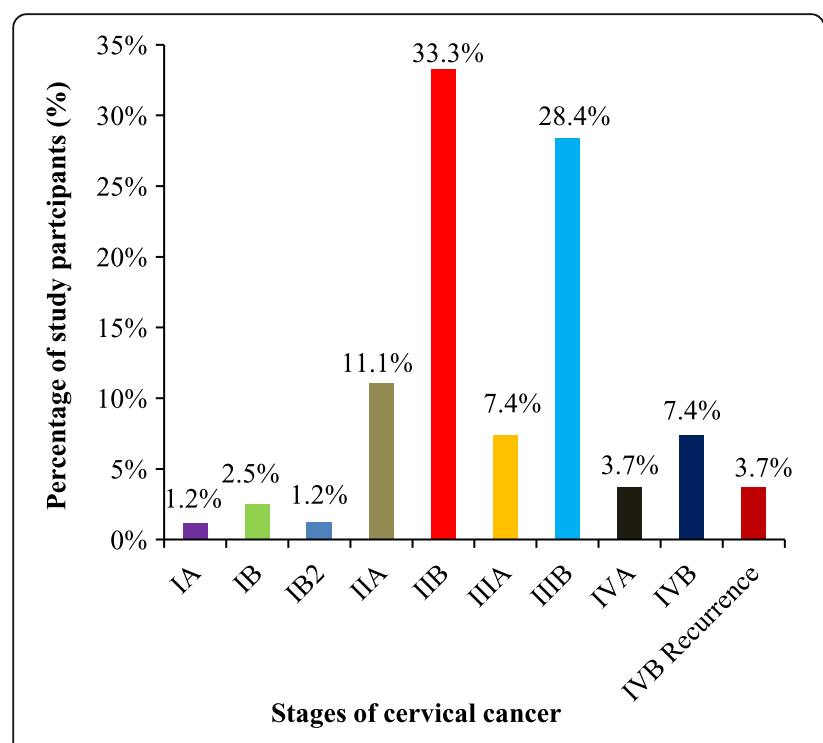

Fig. 2 Stages of cervical cancer identified among study participants

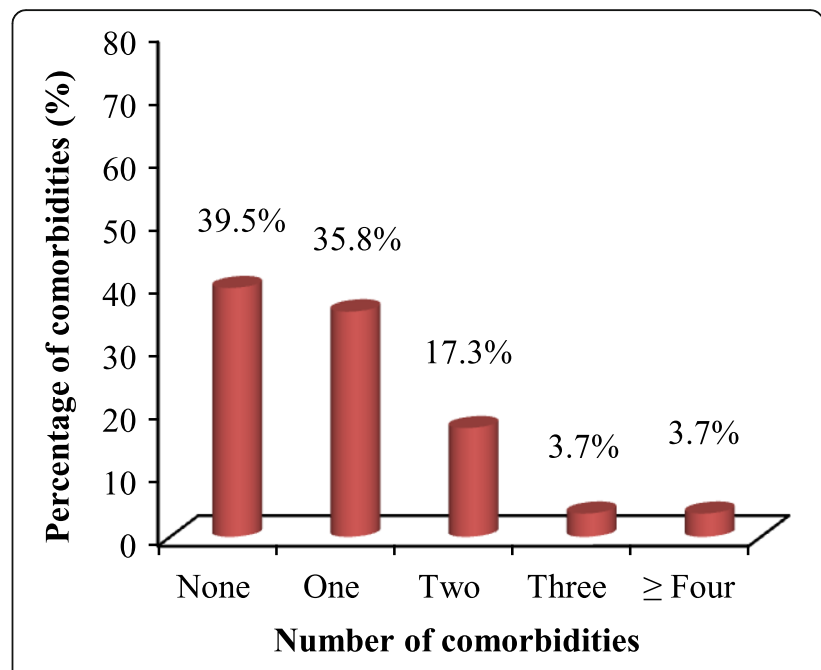

Fig. 3 Percentage of co-morbidities among patients with cervical cancer

Granisetron and dexamethasone combination 32(39.5\%) was the most commonly used prophylactic antiemetic regimen followed by a combination of ondansetron and dexamethasone 18(22.2\%). Conversely, metoclopramide and ondansetron monotherapy were less frequently used in management of chemotherapy-induced emesis among the study subjects (Table 4).

The finding of the study showed that paracetamol, morphine, tramadol and codeine were the most commonly used analgesics among the study participants. Nonetheless, significant proportion (37.4\%) of cervical cancer patients did not receive any form of pain medication (Table 5 ).

\section{Prevalence of drug-related problems}

A total of 215 DRPs were identified from 76 cervical cancer patients, translating to a prevalence of $93.8 \%$ and a mean of $2.65 \pm 1.22$ DRPs per patient. Adverse drug

Table 2 Types of co-morbidities among patients with cervical cancer

\begin{tabular}{lll}
\hline Co-morbidity & Frequency & Percent \\
\hline Anaemia & 21 & 25.9 \\
Retroviral disease & 15 & 18.5 \\
Hypertension & 13 & 16.1 \\
Hydronephrosis & 13 & 16.1 \\
Deep vein thrombosis & 3 & 3.7 \\
Rheumatoid arthritis & 3 & 3.7 \\
Chronic kidney disease & 3 & 3.7 \\
Type II diabetes mellitus & 2 & 2.5 \\
Acute kidney injury & 1 & 1.2 \\
Pulmonary embolism & 1 & 1.2 \\
Sepsis & 1 & 1.2 \\
Gastric ulcer & 1 & 1.2 \\
Goitre & 1 & 1.2 \\
\hline
\end{tabular}




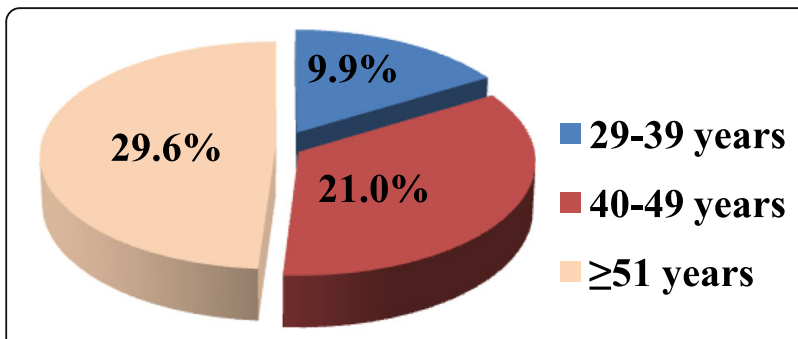

Fig. 4 Percentage of co-morbidities across different age groups of the study participants

reactions, drug interactions and the need for additional drug therapy were the most prevalent DRPs, which accounted for 56(69.1\%), 38(46.9\%) and 32(39.5\%) cases, respectively.

In addition, 26(32.1\%) patients were non-adherent to their medications, and $16(19.8 \%)$ patients received a sub-therapeutic dose of their treatment regimens. Nevertheless, overdosage, improper drug selection, medication use without indication and inappropriate laboratory monitoring accounted for relatively low proportion of drug therapy problems (Table 6).

As illustrated in Fig. 5, most (54.3\%) DRPs were found in the 51 years and above age group while the 4050 years age group accounted for $28.4 \%$. The least proportion of drug-related problems occurred in the 2939 years age group.

As shown in Fig. 6, the predominant proportion of DRPs (48.2\%) was identified in patients treated with chemoradiation regimens while $16.1 \%$ and $13.6 \%$ drug therapy problems were identified in patients who had been managed with radical hysterectomy and brachytherapy, respectively. An equivalent proportion (11.1\%) of drug therapy problems were detected in patients treated with radiotherapy and combination of cisplatin and paclitaxel regimens. In contrast, the least proportion of drug therapy problems were identified in patients treated with the combination of carboplatin and paclitaxel and cisplatin and vinorelbine regimens.

Table 3 Types of regimen used in the management of cervical cancer

\begin{tabular}{lll}
\hline Regimen & Frequency & Percent \\
\hline Chemoradiation (Cisplatin weekly + Radiotherapy) & 41 & 50.6 \\
Hysterectomy & 15 & 18.5 \\
Brachytherapy & 11 & 13.6 \\
Radiotherapy & 10 & 12.3 \\
Cisplatin + Paclitaxel & 9 & 11.1 \\
Carboplatin + Paclitaxel & 5 & 6.2 \\
Cisplatin +Vinorelbine & 1 & 1.2 \\
\hline
\end{tabular}

Table 4 Types of prophylactic antiemetic regimens used in cervical cancer

\begin{tabular}{lll}
\hline Type of antiemetic & Frequency & Percent \\
\hline Granisetron and dexamethasone & 32 & 39.5 \\
Ondansetron and dexamethasone & 18 & 22.2 \\
Metoclopramide and dexamethasone & 4 & 4.9 \\
Metoclopramide & 2 & 2.5 \\
Ondansetron & 1 & 1.2 \\
No-antiemetics given & 24 & 29.6 \\
Total & 81 & 100.0 \\
\hline
\end{tabular}

According to the eight-item Morisky medication adherence scale, $67.9 \%$ of cervical cancer patients were highly adherent, $18.5 \%$ of patients had an average level of medication adherence, while $13.6 \%$ of patients were poorly adherent to their treatment regimens (Fig. 7).

Forgetfulness 18(69.2\%), expensive medications 4(15.4\%) and side effects of medications 4(15.4\%) were the main reasons for non-adherence to medications in the participants. Long duration of therapy and complicated regimens accounted for equal contribution for medication non-adherence while lack of trust on the efficacy of medications was the least common reason for non-adherence in cervical cancer patients (Table 7).

As indicated in Tables 8, 45 drug-drug interactions were identified among the study participants. Ondansetron and dexamethasone were the most common interacting drugs accounting for $12(26.7 \%)$ of the total drug interactions. The other frequently encountered drug interactions were dexamethasone and paclitaxel 4(8.9\%), and codeine and morphine 2(4.4\%). Each of the other pairs of interacting drugs encountered in this study accounted for approximately $2.2 \%$ of the total drug interactions.

In terms of severity, $68.9 \%$ of the drug interactions were significant which required modification or close monitoring of the outcome of the drug interactions. Furthermore, $26.7 \%$ of drug interactions were considered as

Table 5 Analgesics regimens used in cervical cancer at Kenyatta National Hospital

\begin{tabular}{lll}
\hline Type of analgesic & Frequency & Percent \\
\hline Paracetamol & 21 & 25.9 \\
Morphine & 12 & 14.8 \\
Tramadol & 12 & 14.8 \\
Codeine & 11 & 13.6 \\
Diclofenac & 6 & 7.4 \\
Ibuprofen & 5 & 6.2 \\
meloxicam & 3 & 3.7 \\
Etoricoxib & 1 & 1.2 \\
Analgesic not given & 30 & 37.4 \\
\hline
\end{tabular}


Table 6 Categories of drug related problems

\begin{tabular}{lll}
\hline Type of drug related problem & Frequency & Percent \\
\hline Adverse drug reaction & 56 & 69.1 \\
Drug interaction & 38 & 46.9 \\
Need for additional drug therapy & 32 & 39.5 \\
Non-adherence & 26 & 32.1 \\
Sub-therapeutic dose & 16 & 19.8 \\
Overdosage & 15 & 18.5 \\
Improper drug selection & 13 & 16.1 \\
Medication use without indication & 10 & 12.4 \\
Inappropriate laboratory monitoring & 9 & 11.1 \\
\hline
\end{tabular}

minor interactions. However, $4.4 \%$ of drug interactions were serious which necessitate the use of alternative medications in the treatment regimen (Fig. 8).

Of the 166 ADRs identified in this study, the most common were vomiting, nausea, and leucopenia which accounted for 40(49.4\%), 24(29.6\%), and 18(22.2\%) ADRs, respectively. On the other hand, constipation, and thrombocytopenia were the least prevailing ADRs (Table 9).

\section{Predictors of drug related problems}

In the univariable and multivariable binary logistic regression analysis, patients whose cervical cancer was at an advanced stage were 15.4 times $(\mathrm{AOR}=15.4,95 \%$ $\mathrm{CI}=1.3-185.87, p=0.031)$ more likely to have DRPs compared to patients with early stage cervical cancer. Hence, stage of cervical cancer was the only predictor of DRPs in cervical cancer patients (Table 10).

Patients who had been treated with more than five drugs were 2.9 times $(\mathrm{COR}=2.9,95 \% \mathrm{CI}=1.10-7.78$, $p=0.032$ ) more likely to have ADRs as compared to patients treated with less than five medications. In addition, patients with advanced stage disease were 5.9 times $(\mathrm{AOR}=5.9,95 \% \mathrm{CI}=1.43-24.61, p=0.017)$ more likely to have ADRs as compared to patients with early stage of cervical cancer. Nonetheless, patients between 40 and 50 years old were 0.1 times $(\mathrm{AOR}=0.1,95 \% \mathrm{CI}=0.02-$ $0.6, p=0.013$ ) less likely to have ADRs compared to patients with less than 40 years of age (Table 11).

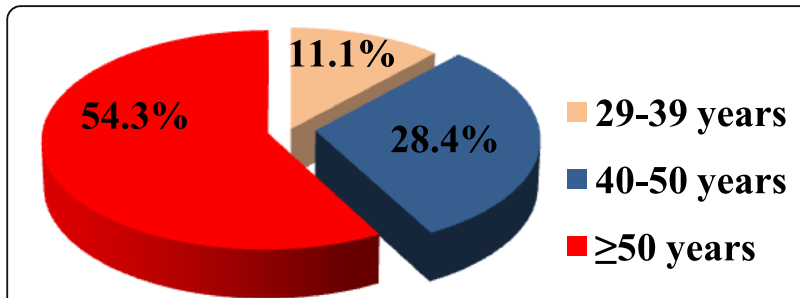

Fig. 5 Percentage of drug-related problems based on age group of cervical cancer patients

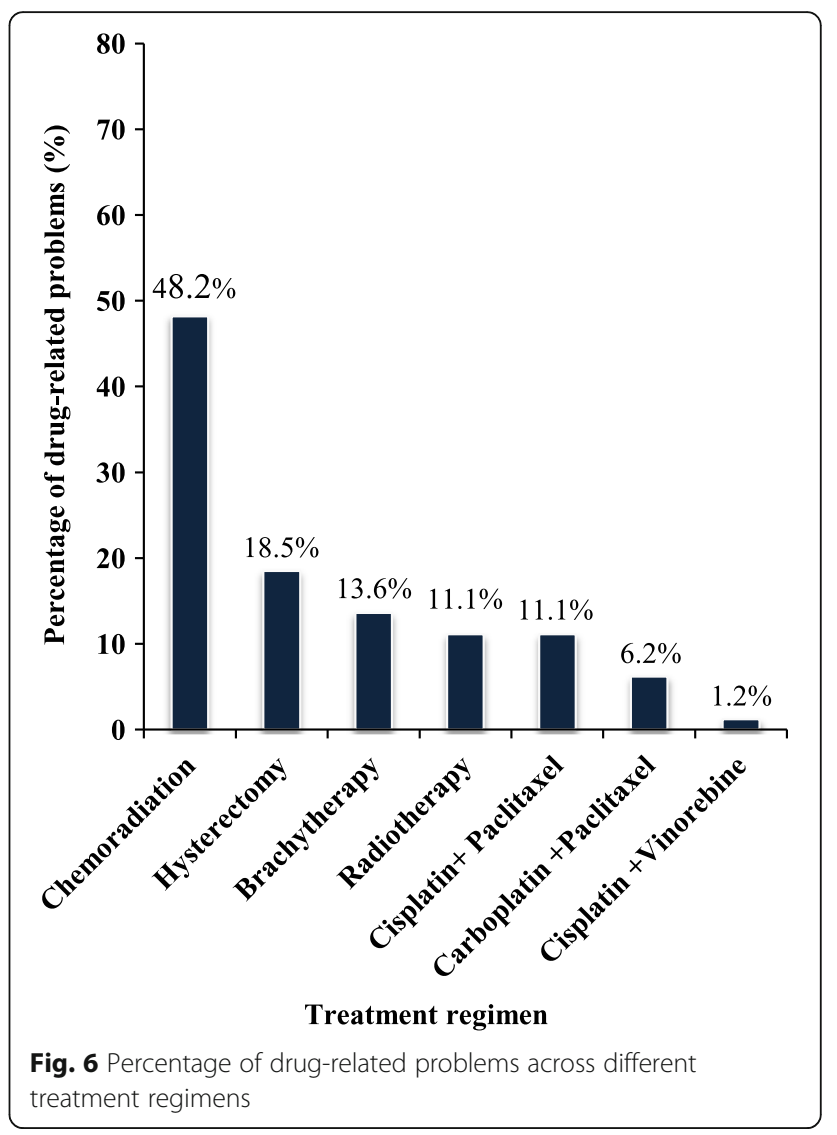

The study revealed that patients with cervical cancer and retroviral disease were 8.8 times $(\mathrm{AOR}=8.8,95 \%$ $\mathrm{CI}=1.22-68.23, p=0.037)$ more likely to have drug interactions as compared to cervical cancer patients without concurrent retroviral disease. The other patient

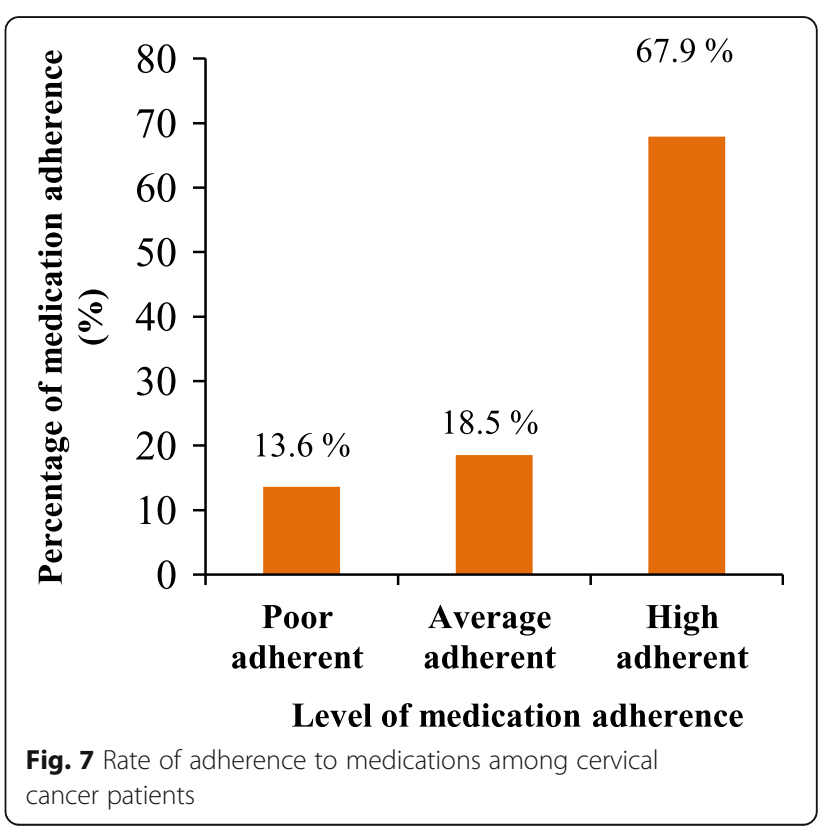


Table 7 Reasons for medications non-adherence among cervical cancer patients $(n=26)$

\begin{tabular}{lll}
\hline Reasons for medications non-adherence & Frequency & Percent \\
\hline Forgetfulness & 18 & 69.2 \\
Expensive medications & 4 & 15.4 \\
side effects of medications & 4 & 15.4 \\
Long duration of therapy & 2 & 7.7 \\
Complicated regimens & 2 & 7.7 \\
Lack of trust on the efficacy of medications & 1 & 3.8 \\
Others & 2 & 7.7 \\
\hline
\end{tabular}

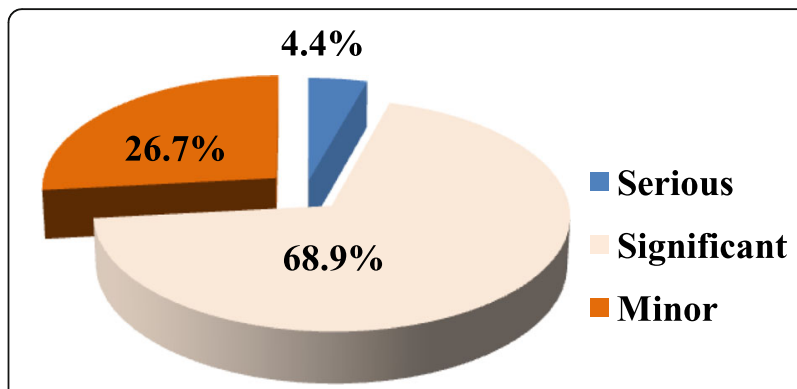

Fig. 8 Severity of drug interactions among women with cervical cancer $(n=45)$

Table 8 Interacting drugs identified among cervical cancer patients $(n=45)$

\begin{tabular}{|c|c|c|c|}
\hline Severity of the interaction & Interacting drugs & Frequency & Percent \\
\hline \multirow[t]{2}{*}{ Serious interaction } & Codeine + Tramadol & 1 & 2.2 \\
\hline & Metronidazole + Erythromycin & 1 & 2.2 \\
\hline \multirow[t]{17}{*}{ Significant interaction } & Amoxicillin + Hydrochlorothiazide & 1 & 2.2 \\
\hline & Zidovudine +cisplatin & 1 & 2.2 \\
\hline & Zidovudine +Cotrimoxazole & 1 & 2.2 \\
\hline & Ceftriaxone + Enoxaparin & 1 & 2.2 \\
\hline & Cisplatin + Gentamicin & 1 & 2.2 \\
\hline & Codeine + Amitryptyline & 1 & 2.2 \\
\hline & Codeine + Morphine & 2 & 4.4 \\
\hline & Dexamethasone + Metronidazole & 1 & 2.2 \\
\hline & Dexamethasone + Tramadol & 1 & 2.2 \\
\hline & Dexamethasone + Paclitaxel & 4 & 8.9 \\
\hline & Diclofenac + Dexamethasone & 1 & 2.2 \\
\hline & Furosemide +Cisplatin & 1 & 2.2 \\
\hline & Nifedipine + Atorvastatin & 1 & 2.2 \\
\hline & Omeprazole + Ranferon & 1 & 2.2 \\
\hline & Ondansetron + Dexamethasone & 12 & 26.7 \\
\hline & Cotrimoxazole +Azithromycin & 1 & 2.2 \\
\hline & Tenofovir + Cisplatin & 1 & 2.2 \\
\hline \multirow[t]{11}{*}{ Minor interaction } & Dexamethasone + Amlodipine & 1 & 2.2 \\
\hline & Diclofenac + Enoxaparin & 1 & 2.2 \\
\hline & Eefavirenz + Paclitaxel & 1 & 2.2 \\
\hline & Efavirenz +Tramadol & 1 & 2.2 \\
\hline & Gabapentin + Paracetamol & 1 & 2.2 \\
\hline & Metronidazole + Diclofenac & 1 & 2.2 \\
\hline & Metronidazole + Gentamicin & 1 & 2.2 \\
\hline & Metronidazole + Ibuprofen & 1 & 2.2 \\
\hline & Metronidzole + Paclitaxel & 1 & 2.2 \\
\hline & Nifedipine + Etoricoxib & 1 & 2.2 \\
\hline & Omeprazole + Diazepam & 1 & 2.2 \\
\hline
\end{tabular}


Table 9 Types of adverse drug reactions in cervical cancer patients $(n=81)$

\begin{tabular}{lll}
\hline Types of adverse drug reaction & Frequency & Percent \\
\hline Vomiting & 40 & 49.4 \\
Nausea & 24 & 29.6 \\
Leucopoenia & 18 & 22.2 \\
Dizziness & 13 & 16.0 \\
Diarrhoea & 10 & 12.3 \\
Abdominal cramp \& bloating & 8 & 9.9 \\
Neutropenia & 8 & 9.9 \\
Tinnitus & 5 & 6.2 \\
Low haemoglobin $_{\text {constipation }}$ & 4 & 4.9 \\
thrombocytopenia $^{\text {Others }}{ }^{\mathrm{a}}$ & 3 & 3.7 \\
\hline
\end{tabular}

athers include hypokalemia, skin rash, oesophageal irritation, bleeding, fatigue, loss of appetite factors did not have statistically significant association with drug interactions (Table 12).

It was noted that patients treated with more than five drugs were 3.6 times $(\mathrm{AOR}=3.6,95 \% \mathrm{CI}=1.24-11.23$, $p=0.026$ ) more likely to have dosing problems as compared to patients treated with less than five medications. Besides, patients who had been managed with cisplatin and paclitaxel regimen were 9.8 times $(\mathrm{AOR}=9.8,95 \%$ $\mathrm{CI}=1.25-77.81, p=0.030)$ more likely to have dosing problems than patients who were not using this regimen (Table 13).

\section{Discussion}

The present study revealed that the mean age of the study participants was $53.3 \pm 11.6$ years, and the predominant portion of the study subjects $47(58.0 \%)$ were 51 years and above. This study is fairly comparable with similar studies conducted in India and Tanzania [20, 21].

Table 10 Univariable and multivariable binary logistic regression analysis of predictors of drug related problems

\begin{tabular}{|c|c|c|c|c|}
\hline \multirow[t]{2}{*}{ Variable } & \multicolumn{2}{|c|}{ Univariable analysis } & \multicolumn{2}{|c|}{ Multivariable analysis } \\
\hline & COR (95\% Cl) & $P$ value & AOR $(95 \% \mathrm{Cl})$ & $P$ value \\
\hline \multicolumn{5}{|l|}{ Age (years) } \\
\hline 29-39 & 1 & & 1 & \\
\hline $40-50$ & $2.6(0.14-46.21)$ & 0.525 & $3.4(0.13-241)$ & 0.263 \\
\hline$\geq 51$ & 1.6(0.15-17.76) & 0.689 & $2.3(0.14-59.22)$ & 0.489 \\
\hline \multicolumn{5}{|l|}{ Education } \\
\hline Illiterate & 1 & & 1 & \\
\hline Literate & $1.9(0.18-18.81)$ & 0.599 & $2.5(0.12-48.81)$ & 0.541 \\
\hline \multicolumn{5}{|l|}{ Income (USD) } \\
\hline$<100$ & 1 & & 1 & \\
\hline $100-200$ & $0.9(0.09-9.47)$ & 0.938 & $1.2(0.12-13.52)$ & 0.855 \\
\hline $200-500$ & $0.2(0.01-2.08)$ & 0.162 & $0.1(0.00-1.13)$ & 0.061 \\
\hline \multicolumn{5}{|l|}{ Marital status } \\
\hline Single & 1 & & 1 & \\
\hline Married & $0.8(0.08-7.23)$ & 0.803 & $0.9(0.14-5.80)$ & 0.927 \\
\hline \multicolumn{5}{|l|}{ Occupation } \\
\hline Unemployed & 1 & & 1 & \\
\hline Employed & $0.1(0.01-1.48)$ & 0.096 & $0.1(0.01-1.41)$ & 1.423 \\
\hline \multicolumn{5}{|l|}{ Co-morbidity } \\
\hline No & 1 & & 1 & \\
\hline Yes & $1.0(0.16-6.56)$ & 0.982 & $0.8(0.11-5.11)$ & 0.767 \\
\hline \multicolumn{5}{|c|}{ Number of medications } \\
\hline$<5$ & 1 & & 1 & \\
\hline$\geq 5$ & $2.6(0.41-16.53)$ & 0.321 & $2.5(0.32-21.61)$ & 0.399 \\
\hline \multicolumn{5}{|c|}{ Stage of cervical cancer } \\
\hline Early stage & 1 & & 1 & \\
\hline Advanced stage & $9.9(1.45-67.58)$ & $0.019^{*}$ & $15.4(1.3-185.87)$ & $0.031^{*}$ \\
\hline
\end{tabular}


Table 11 Univariable and multivariable binary logistic regression analysis of predictors of adverse drug reactions

\begin{tabular}{|c|c|c|c|c|}
\hline \multirow[t]{2}{*}{ Variable } & Univariable analysis & $P$ value & Multivariable analysis & $P$ value \\
\hline & \multicolumn{2}{|l|}{$\operatorname{COR}(95 \% \mathrm{Cl})$} & \multicolumn{2}{|l|}{ AOR $(95 \% \mathrm{Cl})$} \\
\hline \multicolumn{5}{|l|}{ Age (years) } \\
\hline 29-39 & 1 & & 1 & \\
\hline $40-50$ & $0.2(0.02-1.45)$ & 0.102 & $0.1(0.02-0.61)$ & $0.013^{*}$ \\
\hline$\geq 51$ & $0.3(0.03-2.29)$ & 0.227 & $0.2(0.03-1.2)$ & 0.123 \\
\hline \multicolumn{5}{|l|}{ Education } \\
\hline Illiterate & 1 & & 1 & \\
\hline Literate & $1.59(0.41-6.26)$ & 0.509 & $2.4(0.62-9.63)$ & 0.231 \\
\hline \multicolumn{5}{|l|}{ Marital status } \\
\hline Single & 1 & & 1 & \\
\hline Married & $1.7(0.59-4.99)$ & 0.314 & $1.7(0.52-5.93)$ & 0.392 \\
\hline \multicolumn{5}{|l|}{ Occupation } \\
\hline Unemployed & 1 & & 1 & \\
\hline Employed & $0.9(0.08-10.44)$ & 0.925 & $0.8(0.11-9.04)$ & 0.845 \\
\hline \multicolumn{5}{|l|}{ Co-morbidity } \\
\hline No & 1 & & 1 & \\
\hline Yes & $0.8(0.30-2.15)$ & 0.668 & $0.7(0.23-2.31)$ & 0.582 \\
\hline \multicolumn{5}{|l|}{ Number of medications } \\
\hline$<5$ & 1 & & 1 & \\
\hline$\geq 5$ & $2.9(1.12-7.78)$ & $0.032^{*}$ & $2.9(0.91-9.0)$ & 0.071 \\
\hline \multicolumn{5}{|l|}{ Type of cancer } \\
\hline Adenocarcinoma \& Invasive anaplastic carcinoma & 1 & & 1 & \\
\hline Squamous cell carcinoma & $0.4(0.04-3.09)$ & 0.343 & $0.1(0.00-5.42)$ & 0.271 \\
\hline \multicolumn{5}{|l|}{ Stage of cervical cancer } \\
\hline Early stage & 1 & & 1 & \\
\hline Advanced stage & $4.8(1.37-16.79)$ & $0.014^{*}$ & $5.8(1.43-24.61)$ & $0.017^{*}$ \\
\hline
\end{tabular}

COR Crude odds ratio, AOR Adjusted odds ratio, 95\% Cl 95\% confidence interval, " Statistically significant: $P$ value $\leq 0.05$

Late incidence of cervical cancer in the older age may be due to the insidious transformation of the cervical epithelium into cancerous cells by the combined effects of high-risk strains of human papillomavirus (HPV) and other risk factors [22].

Most of the study population had stages IIB (33.3\%) and IIIB (28.4\%) cervical cancer while stages IA and IB2 were the least prevalent. Likewise, a similar study in India showed that stage IIIB (38\%) and stage IIB (35\%) were the most common clinical stages found in cervical cancer patients [21]. The high prevalence of locally advanced stage of cervical cancer patients in our setting may be due to inadequate understanding of the early symptoms of cervical cancer and poor habit of early screening. Moreover, since the majority of the patients had a maximum of primary level education, they might have inadequate understanding of the importance for early Pap smear screening leading to the predominance of advanced stage cervical cancer at the time of diagnosis. Most of the patients in stage I were managed using surgical intervention. According to our eligibility criteria, the patients must be on drug or chemotherapy to be included in the study since we are as assessing drug related problems. Hence, majority of the patients in stage I were not eligible to be included in the study. Moreover, advanced radiological imaging techniques such as PET scan were not available in our facility to screen early stage of precancerous lesion in the cervix. That is why cervical cancer patients with stage I were least prevalent in our setting.

The mortality rate after stage IIIB was very high in our setting due to the progression of the disease. Besides, the rate of transfer to more advanced treatment facilities in advanced stage of the disease was very high. Those are the main reasons why cervical cancer patients with stage IV were very limited in our setting.

Most of the study participants (39.5\%) did not have coexisting co-morbidities. Nonetheless, 35.8\%, 17.3\%, and $3.7 \%$ patients were diagnosed with one, two, three, and four and above co-morbidities, respectively. In contrast, a 
Table 12 Univariable and multivariable binary logistic regression analysis of predictors of drug interactions

\begin{tabular}{|c|c|c|c|c|}
\hline \multirow[t]{2}{*}{ Variable } & Univariable analysis & \multirow{2}{*}{$\begin{array}{l}P \\
\text { value }\end{array}$} & Multivariable analysis & \multirow{2}{*}{$\begin{array}{l}P \\
\text { value }\end{array}$} \\
\hline & COR $(95 \% \mathrm{Cl})$ & & AOR $(95 \% \mathrm{Cl}$ & \\
\hline \multicolumn{5}{|l|}{ Age (years) } \\
\hline $29-39$ & 1 & & 1 & \\
\hline $40-50$ & $1.1(0.22-6.73)$ & 0.957 & $1.9(0.21-19.11)$ & 0.558 \\
\hline$\geq 51$ & $0.2(0.02-1.54)$ & 0.109 & $0.5(0.04-6.11)$ & 0.591 \\
\hline \multicolumn{5}{|l|}{ Education } \\
\hline Illiterate & 1 & & 1 & \\
\hline Literate & $1.1(0.13-10.38)$ & 0.906 & $0.3(0.04-3.02)$ & 0.318 \\
\hline \multicolumn{5}{|l|}{ Marital status } \\
\hline Single & 1 & & 1 & \\
\hline Married & $0.6(0.14-2.77)$ & 0.529 & $1.2(0.23-6.11)$ & 0.851 \\
\hline \multicolumn{5}{|l|}{ Co-morbidity } \\
\hline No & 1 & & 1 & \\
\hline Yes & $6.1(0.71-51.61)$ & 0.101 & $1.2(0.11-16.32)$ & 0.882 \\
\hline Retroviral disease & $14.0(2.93-66.72)$ & $0.001^{*}$ & $8.8(1.22-68.23)$ & $0.037^{*}$ \\
\hline \multicolumn{5}{|l|}{ Number of medications } \\
\hline$<5$ & 1 & & 1 & \\
\hline$\geq 5$ & $0.45(0.11-1.85)$ & 0.269 & $0.2(0.03-1.24)$ & 0.081 \\
\hline \multicolumn{5}{|l|}{ Type of cancer } \\
\hline Adenocarcinoma \& Invasive anaplastic carcinoma & 1 & & 1 & \\
\hline Squamous cell carcinoma & $0.3(0.42-1.62)$ & 0.150 & $0.4(0.02-6.41)$ & 0.723 \\
\hline \multicolumn{5}{|l|}{ Stage of cervical cancer } \\
\hline Early stage & 1 & & 1 & \\
\hline Advanced stage & $0.6(0.11-3.48)$ & 0.597 & $1.5(0.21-11.72)$ & 0.651 \\
\hline
\end{tabular}

similar study in Zimbabwe indicated that majority of the study participants $(79.4 \%)$ had concurrent co-morbidities [23]. In the present study, the most common co-morbidity was anaemia (25.9\%) probably arising from tumourinduced bleeding and iron deficiency secondary to malignancy [24]. This finding is in agreement with an Iranian study in which anaemia was the most common (59.0\%) complication among cervical cancer patients [25]. Contrastingly, a study done in Nigeria identified hypertension (29.8\%) and diabetes mellitus (27.4\%) as the most common co-morbidities in cervical cancer patients [26].

Retroviral disease (18.3\%) was the second leading type of co-morbidity in cervical cancer patients. Correspondingly, a cross-sectional study in Zimbabwe showed that $25.6 \%$ of the study participants had a retroviral disease [27]. In addition, some studies have shown that a strong association exists between human immunodeficiency virus (HIV) infection and cervical cancer with a high prevalence of high-risk HPV DNA in women with HIV infection $[28,29]$. This could probably be due to a weakened immune system secondary to retrovirus infection which puts them at higher risk of HPV infections.
Moreover, the retrovirus may augment the oncogenic activities of HPV which predispose the patients to develop cervical cancer [30]. Although thromboembolic disorders are among the top ranked co-morbidities in cervical cancer patients [31], they had relatively low occurrence among the study participants.

Chemoradiation was the most widely used treatment regimen in the management of cervical cancer at $\mathrm{KNH}$ accounting for $50.6 \%$ of treatment modalities which is higher than in a similar study conducted in Ethiopia (37.6\%) [32]. In the present study, cisplatin and paclitaxel (11.1\%) were the most commonly used combination anticancer agents in the treatment of cervical cancer. Contrastingly, cisplatin and 5-fluorouracil combination regimen was widely used in a Nigerian study [26].

The study showed that granisetron and dexamethasone combination was the most commonly used prophylactic antiemetic in our setting with a usage frequency of 39.5\%, followed by a combination of ondansetron and dexamethasone (22.2\%). Serotonin receptor type $3\left(5-\mathrm{HT}_{3}\right)$ antagonists such as ondansetron and granisetron are the gold standard treatment protocol for chemotherapy-induced nausea and 
Table 13 Univariable and multivariable binary logistic regression analysis of predictors of dosing problems

\begin{tabular}{|c|c|c|c|c|}
\hline \multirow[t]{2}{*}{ Variable } & Univariable analysis & $P$-Value & Multivariable analysis & $P$-value \\
\hline & \multicolumn{2}{|l|}{ COR $(95 \% \mathrm{Cl})$} & \multicolumn{2}{|l|}{$\mathrm{AOR}(95 \% \mathrm{Cl})$} \\
\hline \multicolumn{5}{|l|}{ Age (years) } \\
\hline $29-39$ & 1 & & 1 & \\
\hline $40-50$ & $1.7(0.34-8.15)$ & 0.529 & $2.4(0.32-17.61)$ & 0.412 \\
\hline$\geq 51$ & 1.5(0.32-6.39) & 0.625 & $1.7(0.24-11.52)$ & \\
\hline \multicolumn{5}{|l|}{ Education } \\
\hline Illiterate & 1 & & 1 & \\
\hline Literate & $2.8(0.54-14.11)$ & 0.221 & $4.2(0.60-30.01)$ & 0.161 \\
\hline \multicolumn{5}{|l|}{ Marital status } \\
\hline Single & 1 & & 1 & \\
\hline Married & $1.6(0.54-4.82)$ & 0.386 & $1.2(0.42-3.71)$ & 0.761 \\
\hline \multicolumn{5}{|l|}{ Co-morbidity } \\
\hline No & 1 & & 1 & \\
\hline Yes & $0.4(0.17-1.11)$ & 0.084 & $0.4(0.11-1.32)$ & 0.125 \\
\hline \multicolumn{5}{|l|}{ Number of medications } \\
\hline$<5$ & 1 & & 1 & \\
\hline$\geq 5$ & $3.2(1.15-8.73)$ & $0.026^{*}$ & $3.6(1.24-11.23)$ & $0.026^{*}$ \\
\hline \multicolumn{5}{|l|}{ Type of cancer } \\
\hline Adenocarcinoma \& Invasive anaplastic carcinoma & 1 & & 1 & \\
\hline Squamous cell carcinoma & 1.6(0.29-8.96) & 0.586 & $1.5(0.32-7.43)$ & 0.614 \\
\hline \multicolumn{5}{|l|}{ Stage of cervical cancer } \\
\hline Early stage & 1 & & 1 & \\
\hline Advanced stage & $2.3(0.58-9.33)$ & 0.231 & $3.2(0.72-13.62)$ & 0.121 \\
\hline \multicolumn{5}{|l|}{ Treatment Regimen } \\
\hline Cisplatin + Paclitaxel & $3.7(0.9-16.5)$ & 0.079 & $9.8(1.25-77.81)$ & $0.030^{*}$ \\
\hline
\end{tabular}

COR Crude odds ratio, AOR Adjusted odds ratio, $95 \% \mathrm{Cl} 95 \%$ confidence interval, ${ }^{*}$ Statistically significant: $P$ value $\leq 0.05$

vomiting due to superior efficacy and better tolerability of side effects as compared to conventional antiemetics [33]. The $5-\mathrm{HT}_{3}$ receptor antagonists are also preferred over dopamine receptor antagonists since they are devoid of extrapyramidal side effects [34]. Previous studies reported that the efficacy of $5-\mathrm{HT}_{3}$-receptor antagonists was augmented with the addition of dexamethasone [35]. Although equivalent doses of different $5-\mathrm{HT}_{3}$-receptor antagonists had comparable efficacy [34], a combination of ondansetron and dexamethasone use was not common in our setting due to drug-drug interaction. This finding corroborated the frequent use of granisetron and dexamethasone combination in our setting which is in line with the standard protocol [35].

The finding of $93.8 \%$ prevalence of DRPs in our setting is fairly higher than in a similar Norwegian study $(73 \%)$ [36]. However, the finding of this study is comparable with a similar study done in Nigeria which showed that the prevalence of DRPs in cervical cancer patients was $89.2 \%$ [26]. Besides, a mean of $2.65 \pm 1.22$ drug therapy problems were identified in the study population which is relatively higher than 2.1 DRPs detected per patient in a study done in Norway [36]. The higher prevalence DRPs in our setting may be due to inadequate understanding of the disease and medications among the patients and absence of local standard treatment protocols for cervical cancer patients.

There was a high preponderance of DRPs in the 51 years and above age group that accounted for $54.3 \%$ of the cases. This could probably be due to the high prevalence of co-morbidities in patients 51 years and above (29.6\%) and the ageing of the metabolising organs which predispose the patient to DRPs.

Adverse drug reactions (69.1\%) and drug interactions (46.9\%) were the most prevalent DRPs, a finding that is in agreement with a similar study done in Nigeria [26] but higher than a finding reported by a Singaporean study [37]. The high incidence of ADRs may be attributed to the complexity and immunosuppressive effects of cancer treatment regimens.

Nausea and vomiting were among the top ranking ADRs. These findings are in line with a study done in 
India in which nausea and vomiting were prevalent among cancer patients treated with anticancer agents $[38,39]$. This could probably be linked to the emetogenic potential of cisplatin and paclitaxel and the cytotoxic effects of anticancer agents in the highly proliferating cells of the gastrointestinal tract. Additionally, the higher incidence of nausea and vomiting could be due to poor management of delayed nausea and vomiting secondary to the anticancer agents.

Although morphine, tramadol and codeine were the most commonly used pain medications, only $3.7 \%$ of the population had constipation as ADR. In our facility, these pain medications were usually given along with stool softeners and this clinical practice could probably be the main reason why constipation due to these opioids-based pain medications was not a major issue in our setting. Pain control was in line with WHO guideline for pain control in cancer patients and hence we didn't notice any discrepancies except drug interactions due to the combined use of two opioid analgesics (i.e. codeine and morphine) among $4.4 \%$ of the study participants. Pain medications were considered as essential drugs for palliative care treatment in cancer patients in Kenya [40]. Hence, almost all public healthcare facilities offering cancer treatment were universally accessible to these essential drugs. However, controlled pain medications such as opioid analgesics were accessed to cancer patients under supervised prescription by the palliative care specialists. In addition, being controlled drugs those medicines may not be available at the lower level of healthcare facilities.

When age was taken into consideration, elderly patients (age $\geq 51$ years) had encountered most (40.7\%) of the ADRs. This finding is similar to that reported by Poddar et al. [41] where the incidence of ADRs among geriatric patients was significantly higher than other age groups. This may be due to diminished metabolising capacity and excretory functions in the elderly patients leading to accumulation of drugs in the body and thus increasing the risk of ADRs [42].

Chemoradiation was the most commonly used treatment modality and was also associated with the majority of the ADRs in our setting which is comparable with other studies [43, 44]. Furthermore, the present study revealed that $33.3 \%$ and $28.4 \%$ patients had stage IIB and IIIB cervical cancer, respectively which were categorised as locally advanced cervical cancer. It has been shown that chemoradiation is the standard treatment of choice in the management of locally advanced cervical cancer due to the overall tolerability of side effects and enhancement of survival $[45,46]$. This could probably be the reason why this regimen was widely used in our setting and was therefore associated with the majority of the ADRs.
Due to the complexity of the chemotherapeutic regimens, cancer patients are susceptible to potential drug interactions. Not surprisingly, this study unveiled that $46.9 \%$ of cervical cancer patients had potential drug interactions in the treatment regimens. A similar study in Dutch reported $46 \%$ prevalence of potential drug interactions among cancer patients [47]. This high prevalence of drug interactions may step up the adverse effects of anticancer agents or lessen the therapeutic outcomes of the treatment regimen. With regard to severity, 68.9\% significant drug interactions were detected from the treatment regimens of cervical cancer patients which is slightly higher than a study done in Tehran that reported a prevalence of $59.7 \%$ [48]. However, only $4.4 \%$ of the drug interactions were identified as serious drug interaction which necessitates use of alternative drug regimens.

Ondansetron and dexamethasone were the most common interacting drugs accounting for $26.7 \%$ of the total drug interactions. Previous studies reported that premedication of dexamethasone diminished the efficacy of paclitaxel in breast cancer and ovarian carcinoma [49, 50]. According to the findings of the present study, dexamethasone and paclitaxel accounted for $8.9 \%$ of the drug interactions. Thus, it is plausible to assume that the prophylactic use of dexamethasone antiemetic in paclitaxel-based regimens might reduce the antitumor activity of paclitaxel in cervical cancer patients.

A cross-sectional descriptive study conducted in Ethiopia revealed that $69.7 \%$ of cervical cancer patients were adherent to their treatment regimens while $30.3 \%$ of patients were non-adherent [32]. Similarly, $67.9 \%$ of cervical cancer patients were adherent to their treatment regimens in our setting. However, the rate of medication adherence (61.1\%) among cervical cancer patients in India was slightly lower than our setting [51]. This could probably be due to the availability of better facilities to strengthen the awareness of the patients about their medications adherence at the Oncology Units of KNH.

Among 26 non-adherent cervical cancer patients, forgetfulness (69.2\%), expensive medications (15.4\%) and side effects of medications $(15.4 \%)$ were the main reasons for non-adherence while long duration of therapy and complicated regimens contributed equivalently (7.7\%) to medication non-adherence. On the other hand, lack of trust on the efficacy of medicines was the least common reason for non-adherence in cervical cancer patients at KNH. Comparatively, a study from Ethiopia revealed that long duration of therapy, side effects of the medication and expensive medication were among the top-ranking reasons for medication non-adherence in cervical cancer patients [32].

The present study revealed that patients with advanced stage cervical cancer were 15.4 times $(\mathrm{AOR}=15.4,95 \%$ 
$\mathrm{CI}=1.3-185.87, p=0.031)$ more likely to have DRPs as compared to patients with early stage cervical cancer. In addition, patients with advanced stage cervical cancer were 5.9 times $(\mathrm{AOR}=5.9,95 \% \mathrm{CI}=1.4-24.6$, $p=0.017$ ) more likely to experience ADRs as compared to patients with early stage disease.

Koh et al. [52] reported that multiple uses of drugs were a significant predictor of the incidence of DRPs. Hence, the higher likelihood of DRPs in the advanced stage cervical cancer may be due to multiple medications secondary to the complexity of the conditions which predispose the patients to DRPs. Likewise, stage of cervical cancer was the only predictor of DRPs in cervical cancer patients. Previous studies in Sweden [53], Malaysia [54], Nigeria [26] and Ethiopia [55] reported that polypharmacy and presence of co-morbidities were positively associated with DRPs. Conversely, our study revealed that number of medications and presence of co-morbidities were not statistically significant predictors of drug related problems.

Patients who had been treated with more than five drugs were more likely to have ADRs and dosing problems and less likely to have inappropriate laboratory monitoring as compared to patients treated with less than five medications. Similarly, previous study in Pakistan showed that polypharmacy was positively associated with ADRs [56]. Moreover, a similar study in Singapore showed that chronic use of five or more drugs was associated with the presence of DRPs [37]. The higher likelihood of having ADRs may plausibly be due to the enhanced pharmacological effects of the drugs secondary to the undesired drug interaction at the level of metabolism and excretion.

In the univariable logistic regression analysis, patients who had been managed with cisplatin and paclitaxel regimen were 9.8 times more likely to have dosing problems. Additionally, cervical cancer patients with the retroviral disease were 8.8 times $(\mathrm{AOR}=8.8,95 \% \mathrm{CI}=1.2-68$, $p=0.037)$ more likely to have drug interactions as compared to patients without concurrent retroviral disease. Conversely, the other sociodemographic factors did not have statistically significant association with drug interactions. The higher likelihood of having drug interactions may plausibly be due to the complexity of drug regimens in the management of both conditions. Previous studies showed that an increased risk of nephrotoxicity due to the combination tenofovir and platinum analogues such as cisplatin particularly in patients with renal insufficiency. Moreover, there was a mounting report of haematological toxicity with a combination of taxane class of anticancer agents such as paclitaxel and zidovudine [57]. Since the majority of cervical cancer patients with retroviral disease were treated with tenofovir and cisplatin-based regimens in our setting, they were a higher risk of having nephrotoxicity due to drug-drug interaction between the anticancer and anti retroviral agents. Hence, having a retroviral disease as co-morbidity in cervical patients might be an important predictor for drug interaction.

\section{Conclusion}

Adverse drug reactions, drug interactions, and need of additional drug therapy were the most common DRPs identified among cervical cancer patients. Nausea and vomiting were the most prevalent ADRs among the study participants. In the multivariable binary logistic regression analysis, advanced stage of cervical cancer and treatment with more than five drugs were significant predictors of ADRs. Likewise, coexisting retroviral disease and treatment with more than five medications were predictors of drug interactions and dosing problems, respectively.

\section{Abbreviations}

ADRs: Adverse Drug Reactions; AOR: Adjusted Odds Ratio; Cl: Confidence Interval; COR: Crude Odds Ratio; DRPs: Drug Related Problems; ESMO: European Society for Medical Oncology; GFR: Glomerular Filtration Rate.; NCCN: National Compressive Cancer Network.; USD: United States Dollar.; WHO: World Health Organization

\section{Acknowledgments}

The authors would like to acknowledge AFIMEGQ Programme for financial support towards this project.

\section{Funding}

The study was conducted under the financial support of Africa for Innovation, Mobility, Exchange, Globalization and Quality (AFIMEGQ) Programme.

\section{Availability of data and materials}

The datasets used and/or analysed during the current study are available from the corresponding author on reasonable request.

\section{Author's contribution}

AD conducted the actual study and the statistical analysis. AD, PN, IW and PK were involved in developing the idea, designing of the study and the write up of the manuscript. All authors approved the submitted version of the manuscript.

\section{Ethics approval and consent to participate}

Ethical approval of the study protocols was obtained from the Kenyatta National Hospital/University of Nairobi Ethics and Research Committee (Protocol number: P963/12/2016). Before data collection, informed written consent was obtained from the study participants. Each patient was notified about the objective of the study, procedures for selection and assurance of confidentiality. To ensure confidentiality of the patients' information, the name and address of the patients were not recorded during data collection.

Consent for publication

Not applicable.

\section{Competing interests}

The authors declare that they have no competing interest.

\section{Publisher's Note}

Springer Nature remains neutral with regard to jurisdictional claims in published maps and institutional affiliations.

\section{Author details}

${ }^{1}$ Department of Pharmaceutics and Pharmacy Practice, University of Nairobi, College of Health Sciences, School of Pharmacy, P.O. Box 19676-00202, Nairobi, Kenya. ${ }^{2}$ Department of Pharmaceutical Chemistry, University of Nairobi, College of Health Sciences, School of Pharmacy, Nairobi 19676-00202, Kenya. ${ }^{3}$ Kenyatta National Hospital, Division of Pharmacy, Nairobi 20723-00202, Kenya. 
Received: 7 August 2017 Accepted: 13 October 2017

Published online: 18 October 2017

\section{References}

1. World Health Organization. The Pursuit of responsible use of medicines: sharing and learning from Country experiences [Internet]. Amasterdam; 2012. Available from: http://apps.who.int/iris/bitstream/10665/75828/1/ WHO_EMP_MAR_2012.3_eng.pdf?ua=1

2. World Health Organization. Essential medicines and health products [Internet]. 2015 [cited 2016 Oct 28]. Available from: http://www.who.int/ medicines/areas/rational use/en/

3. Ruths S, Viktil KK, Blix HS. Classification of drug-related problems. Tidsskr Nor Laegeforen. 2007;127(23):3073-6.

4. Cipolle R, Strand L, Morley P. Pharmaceutical care practice: the patientcentered approach to medication management services. 3rd ed. USA: McGraw-hill Education; 2012.

5. Jaehde U, Liekweg A, Simons S, Westfeld M. Minimising treatment-associated risks in systemic cancer therapy. Pharm World Sci. 2008;30(2):161-8.

6. Cehajic I, Bergan S, Bjordal K. Pharmacist assessment of drug-related problems on an oncology ward. Eur J Hosp Pharm. 2015;22(4):194-7.

7. Iftikhar A, Jehanzeb K, Ullah A. Clinical pharmacy services in medical oncology unit, Peshawar, Pakistan. Pharmacologyonline. 2015;1:10-2.

8. Ambili R. Toxicities of anticancer drugs and its management. Int J Basic Clin Pharmacol. 2012;1(1):2-12.

9. Ikushima H, Osaki K, Furutani S, Yamashita K, Kawanaka T, Kishida Y, et al. Chemoradiation therapy for cervical cancer: toxicity of concurrent weekly cisplatin. Radiat Med. 2006;24(2):115-21.

10. Koh Y, Kutty FB, Li SC. Drug-related problems in hospitalized patients on polypharmacy: the influence of age and gender. Ther Clin Risk Manag. 2005; 1(1):39-48.

11. Kasiulevicius V, Sapoka V, Filipaviciute R. Sample size calculation in epidemiological studies. Gerontologija. 2006;7(4):225-31.

12. Ministry of Health. National Guidelines for Cancer Management Kenya [Internet]. 2013 [cited 2017 Jun 15]. Available from: http://kehpca.org/wpcontent/uploads/National-Cancer-Treatment-Guidelines2.pdf

13. National Compressive Cancer Network. NCCN Clinical Practice Guidelines in Oncology: Cervical Cancer. [Internet]. 2016 [cited 2017 Jun 15]. Available from: https://www.ncen.org/professionals/physician_gls/pdf/cervical.pdf

14. Marth C, Landoni F, Mahner S, McCormack M, Gonzalez-Martin A, Colombo N. Cervical cancer: ESMO Clinical Practice Guidelines for diagnosis, treatment and follow-up. Ann Oncol. 2017:28(Supplement 4):iv72-83.

15. World Health Organization. Cancer pain relief: with a guide to opioid availability [Internet]. 1996 [cited 2016 Nov 30]. Available from: http://apps. who.int/iris/bitstream/10665/37896/1/9241544821.pdf

16. Oliveira-Filho AD, Barreto-Filho JA, Neves SJ, Lyra Junior DP. Association between the 8-item Morisky medication adherence scale (MMAS-8) and blood pressure control. Arq Bras Cardiol. 2012;99(1):649-58.

17. Levey AS, Coresh J, Greene T, Marsh J, Stevens LA, Kusek JW, et al. Expressing the modification of diet in renal disease study equation for estimating glomerular filtration rate with standardized serum creatinine values. Clin Chem. 2007;53(4):766-2

18. Du Bois D, Du Bois EFA. Formula to estimate the approximate surface area if height and weight be known. 1916. Nutrition. 1989;5(5):303-11.

19. van Warmerdam $L$, Rodenhuis S, ten Bokkel Huinink WW, Maes RA, Beijnen $\mathrm{JH}$. The use of the Calvert formula to determine the optimal carboplatin dosage. J Cancer Res Clin Oncol. 1995;121(8):478-86.

20. Majinge PM. Treatment outcome of cervical cancer patients at ocean road cancer institute, Dar es salaam [internet]. Muhimbili University of Health and Allied. Sciences. 2011; Available from: http://ihi.eprints.org/966/

21. Chauhan R, Trivedi V, Rani R, Singh U. A hospital based study of clinical profile of cervical cancer catients of Bihar, an eastern state of India. Womens Heal Gynecol. 2016;2(2):1-4.

22. Burd EM. Human papillomavirus and cervical cancer. Clin Microbiol Rev. 2003;16(1):1-17.

23. Kagura Y. A study to determine the relationship between prevalence of late stage diagnosis of cervical cancer and number of comorbid illnesses in women aged 65 years and above in Zimbabwe [internet]. University of Zimbabwe; 2015. Available from: http://ir.uz.ac.zw/jspui/bitstream/10646/ 2901/1/Kagura_A-Study_to_Determine_The_Relationship_Between_ Prevalence_Of_Late_Stage_Diagnosis_Of_Cervical_Cancer_.pdf
24. Candelaria M, Cetina L, Duenas-Gonzalez A. Anemia in cervical cancer patients: implications for iron supplementation therapy. Med Oncol. 2005; 22(2):161-8

25. Shahbazian H, Marrefi MS, Arvandi S, Shahbazian N. Investigating the prevalence of anemia and its relation with disease stage and patients ' age with cervical cancer referred to Department of Radiotherapy and Oncology of Ahvaz Golestan hospital during 2004-2008. Int J Pharm Res Allied Sci. 2016;5(2):190-3.

26. Mustapha S. Drug related problems in cervical cancer patients on chemotherapy in Ahmadu Bello University teaching hospital, Nigeria [internet]. Near East University; 2016. Available from: http://docs.neu.edu.tr/ library/6405400533.pdf

27. Chirenje ZM, Loeb L, Mwale M, Nyamapfeni P, Kamba M, Padian N. Association of cervical SIL and HIV-1 infection among Zimbabwean women in an HIV/STI prevention study. Int J STD AIDS. 2002:13(11):765-8.

28. Holmes RS, Hawes SE, Toure P, Dem A, Feng Q, Weiss NS, et al. HIV infection as a risk factor for cervical cancer and cervical intraepithelial neoplasia in Senegal. Cancer Epidemiol Biomark Prev. 2009;18(9):2442-6.

29. Adjorlolo-Johnson G, Unger ER, Boni-Ouattara E, Touré-Coulibaly K, Maurice C, Vernon SD, et al. Assessing the relationship between HIV infection and cervical cancer in Côte d'Ivoire: a case-control study. BMC Infect Dis. 2010;10:242.

30. Mandelblatt JS, Kanetsky P, Eggert L, Gold KIHIV. Infection a cofactor for cervical squamous cell neoplasia? Cancer Epidemiol Biomark Prev. 1999;8(1):97-106.

31. Barbera L, Thomas G. Venous thromboembolism in cervical cancer. Lancet Oncol. 2008;9(1):54-60.

32. Gebre Y, Zemene A, Fantahun A, Aga F. Assessment of treatment compliance and associated factors among cervical cancer patients in Tikur Anbessa specialized hospital, oncology unit, Ethiopia 2012. Int J Cancer Stud Res. 2015;4:67-74.

33. Hesketh $\mathrm{PJ}$. Comparative review of $5-\mathrm{HT} 3$ receptor antagonists in the treatment of acute chemotherapy-induced nausea and vomiting. Cancer Investig. 2000;18:163-73.

34. Goodin S, Cunningham R. 5-HT(3)-receptor antagonists for the treatment of nausea and vomiting: a reappraisal of their side-effect profile. Oncologist. 2002;7(5):424-36.

35. National Compressive Cancer Network. NCCN Clinical Practice Guideline in Oncology:Antiemsis version1 [Internet]. 2015 [cited 2017 Jul 23]. Available from: http://www.prolekare.cz/dokumenty/Antiemetikum guidelines.pdf

36. Cehajic I, Bergan S, Bjorda K. Pharmacist assessment of drug-related problems on an oncology ward. Eur J Hosp Pharm. 2015;22(4):1-4.

37. Yeoh TT, Tay XY, Si P, Chew L. Drug-related problems in elderly patients with cancer receiving outpatient chemotherapy. J Geriatr Oncol. 2015;6(4):280-7.

38. Wahlang JB, Laishram PD, Brahma DK, Sarkar C, Lahon J, Nongkynrih BS. Adverse drug reactions due to cancer chemotherapy in a tertiary care teaching hospital. Ther Adv Drug Saf. 2017;8(2):61-6.

39. Sharma A, Kumari KM, Manohar HD, Bairy KL, Thomas J. Pattern of adverse drug reactions due to cancer chemotherapy in a tertiary care hospital in South India. Perspect Clin Res. 2015;6(2):109-15.

40. Ministry of Health. Kenya Essential Medicines List [Internet]. 2016 [cited 2017 Sep 21]. Available from: http://apps.who.int/medicinedocs/documents/ s23035en/s23035en.pdf

41. Poddar S, Sultana R, Sultana R, Akbor MM, Azad MAK, Hasnat A. Pattern of adverse drug reactions due to cancer chemotherapy in tertiary care teaching Hospital in Bangladesh. Dhaka Univ. J Pharm Sci. 2009;8(1):11-6.

42. Klotz U. Pharmacokinetics and drug metabolism in the elderly. Drug Metab Rev. 2009;41(2):67-76.

43. Duenas-Gonzalez A, Cetina L, Coronel J, Gonzalez-Fierro A. The safety of drug treatments for cervical cancer. Expert Opin Drug Saf. 2016;15(2):169-80.

44. Surendiran A, Balamurugan N, Gunaseelan K, Akhtar S, Reddy KS, Adithan C. Adverse drug reaction profile of cisplatin-based chemotherapy regimen in a tertiary care hospital in India: an evaluative study. Indian J Pharmacol. 2010; 42(1):40-3.

45. Todo $Y$, Watari H. Concurrent chemoradiotherapy for cervical cancer: background including evidence-based data, pitfalls of the data, limitation of treatment in certain groups. Chin J Cancer Res. 2016;28(2):221-7.

46. Lukka H, Hirte H, Fyles A, Thomas G, Elit L, Johnston M, et al. Concurrent cisplatin-based chemotherapy plus radiotherapy for cervical cancer-a metaanalysis. Clin Oncol. 2002;14(3):203-12.

47. van Leeuwen RW, Brundel DH, Neef C, van Gelder T, Mathijssen RH, Burger DM, et al. Prevalence of potential drug-drug interactions in cancer patients treated with oral anticancer drugs. Br J Cancer. 2013;108(5):1071-8. 
48. Tavakoli-Ardakani M, Kazemian K, Salamzadeh J, Mehdizadeh M. Potential of drug interactions among hospitalized cancer patients in a developing country. Iran J Pharm Res. 2013;12:175-82.

49. Sui M, Chen F, Chen Z, Fan W. Glucocorticoids interfere with therapeutic efficacy of paclitaxel against human breast and ovarian xenograft tumors. Int J Cancer. 2006;119:712-7.

50. Hou WJ, Guan JH, Dong Q, Han YH, Zhang R. Dexamethasone inhibits the effect of paclitaxel on human ovarian carcinoma xenografts in nude mice. Eur Rev Med Pharmacol Sci. 2013;17(21):2902-8.

51. Dutta S, Biswas N, Muhkherjee G. Evaluation of socio-demographic factors for non-compliance to treatment in locally advanced cases of cancer cervix in a rural medical College Hospital in India. Indian J Palliat Care. 2013;19(3):158-65.

52. Koh Y, Kutty FB, Li SC. Drug-related problems in hospitalized patients on polypharmacy: the influence of age and gender. Ther Clin Risk Manag. 2005; 1(1):39-40.

53. Peterson C, Gustafsson M. Characterisation of drug-related problems and associated factors at a clinical pharmacist service-naive Hospital in Northern Sweden. Drugs Real World Outcomes. 2017;4(2):97-107.

54. Zaman Huri H, Hui Xin C, Sulaiman CZ. Drug-related problems in patients with benign prostatic hyperplasia: a cross sectional retrospective study. PLoS One. 2014;9(1):e86215.

55. Sisay EA, Engidawork E, Yesuf TA, Ketema EB. Drug related problems in chemotherapy of cancer patients. J Cancer Sci Ther. 2015;7(2):55-9.

56. Ahmed B, Nanji K, Mujeeb R, Patel MJ. Effects of polypharmacy on adverse drug reactions among geriatric outpatients at a tertiary care hospital in Karachi: a prospective cohort study. PLoS One. 2014;9(11):e112133.

57. Makinson A, Pujol JL, Le Moing V, Peyriere H, Reynes J. Interactions between cytotoxic chemotherapy and antiretroviral treatment in human immunodeficiency virus-infected patients with lung cancer. J Thorac Oncol. 2010;5(4):562-71.

\section{Submit your next manuscript to BioMed Central and we will help you at every step:}

- We accept pre-submission inquiries

- Our selector tool helps you to find the most relevant journal

- We provide round the clock customer support

- Convenient online submission

- Thorough peer review

- Inclusion in PubMed and all major indexing services

- Maximum visibility for your research

Submit your manuscript at www.biomedcentral.com/submit 